\title{
Agriculture Land and Technology: Agricultural Production in the Welfare Improvement
}

\author{
Abid Muhtarom ${ }^{\# 1}$, Tri Haryanto *2 \\ ${ }^{\#}$ Faculty of Economics, Islamic University of Lamongan \\ Lamongan, Indonesia \\ ${ }^{1}$ abideunisula.ac.id \\ * Faculty of Economics and Business, Airlangga University Surabaya \\ Surabaya, Indonesia
}

\begin{abstract}
Agriculture is an important factor in the economy of the state of Indonesia, most of the livelihoods of Indonesian society in agriculture. Agriculture in Indonesia has experienced a food productivity dilemma in which there are five problems to overcome in order to produce abundant agricultural products. The first factor causing agricultural problems is irrigation factor that is damaged even 53\% of damaged irrigation network. The second factor is less absorbed rice seed. The third factor is fertilizer management where if not organized then farmers will be late to get fertilizer, this will potentially decrease of agricultural product. The fourth factor is the procurement of agricultural machinery or modernization of the farming system, and the last fifth factor is the extension worker in charge of providing knowledge and bridging from farmers to government. This is what makes the problems and lead directly to the welfare of farmers to be reduced.
\end{abstract}

High agricultural production can boost agricultural welfare in the economic field. Indonesian government policy to increase high agricultural yields one of them with the increase and expansion of agricultural land. Results analysis correlation analysis between response variables, parameter estimates, and model formation.

The results can be concluded from all the above variables can be seen that the problems that must be addressed above must be addressed immediately because the impact resulting from agricultural dilemma have significant effect, agricultural land and technology to agricultural welfare production. This can result in the decrease of agricultural products and unemployement caused by the growing technology and also the narrowing of land in particular especially on the island of Java. Variable Harvest Area in general gives a significant effect on the amount of production and welfare. Similarly, variable use of technology turned out to have a significant influence on the amount of production and welfare. The interaction between harvested area variables and the provision of technology did not provide significant differences on the amount of production and welfare.

Keywords - Agricultural Land, Technology, Agricultural Production And Welfare.

\section{PRELIMINARY}

Agriculture is the largest livelihood of the Indonesian people. The large number of people who rely on this sector to make two sides of the sharp blade. Where one of the knives gives a positive benefit one of them the absorption of employment on the other hand to make the sector negative, because the development of other sectors can be hampered. Farmland in Indonesia is fertile cause the types of tropical plants can thrive here, but the problems that arise are also very large where the number of agricultural fields that bermah function to the residential and industrial sector, while our agricultural stocks continue to decline if not overcome will affect the food supply in the country. The economic laws of demand and supply will be very applicable if the problem continues.

Agriculture is an important factor in the economy of the state of Indonesia, most of the livelihoods of Indonesian society in agriculture. Agriculture in Indonesia has experienced a food productivity dilemma in which there are five problems to overcome in order to produce abundant agricultural products. The first factor causing agricultural problems is irrigation factor that is damaged even $53 \%$ of damaged irrigation network. The second factor is less absorbed rice seed. The third factor is fertilizer management where if not organized then farmers will be late to get fertilizer, this will potentially decrease of agricultural product. The fourth factor is the procurement of agricultural machinery or modernization of the farming system, and the last fifth factor is the extension worker in charge of providing knowledge and bridging from farmers to government. This is what makes the problems and leads directly to the welfare of farmers is reduced ([3])

As with the During the last years research, the interest of policy-makers in short supply chain has grown. It appears to be a tool able to incentivize a sustainable agricultural productions and to provide environmental, economic and social benefits. In fact, 
the short supply chain of reducing costs, which is the short supply chain of the product of the consumer products, creates a positive environmental externalities and, above all, promotes the local areas. This work highlights the marketing of the supply chain and its importance in influencing the concept of sustainable development in the supply chain. Moreover, this work aims to find evidence for the development of the new forms of marketing, the potential lies in the customers' attention to ethical and environmental issues and their need for natural and healthy food ([3])

Technology is an important factor in agricultural activities because it can be used for time efficiency and effectiveness of employment in agricultural jobs. If this is all running well then it can be concluded agricultural products can be obtained. production in the agricultural sector can do one of them using road improvement technology, so as to increase agricultural production in Indonesia. Not only technology can boost agricultural production, but agricultural land is also needed in agricultural production activities, the government has introduced intensification and extensification programs to address agricultural shortages ([4])

The journal research in an attempt to go beyond the so called 'smart smart' subsidies, Nigeria has embarked on a potentially innovative mobile phonebased subsidy program that provides fertilizer and seeded subsidies through electronic vouchers. In this article, we examined the productivity and welfare eff ects of the program using household-level data from rural Nigeria. The article employed instrumental variable regression approach to control for the potential endogeneity of the input subsidy program. Our results suggest that the program is effective in improving productivity and welfare outcomes of bene fi ciary smallholders. The size of the estimated effects suggests a large improvement in productivity and welfare outcomes. Moreover, the distributional e ff ects of the program suggest no heterogeneity e ff ects based on gender and farm land size. These results are robust to use alternative measurements of program partic-ipation. The bene fi t-cost ratio of 1.11 suggests that the program is marginally cost-e ff ective. Overall, our results suggest that while improving the average productivity is the best outcome for improving food security, improving the distributional outcome of the program by targeting the most disadvantaged groups would maximize the program's contribution to food security and poverty reduction ([2])

Function Agricultural land and technology not only as a part of agricultural production alone, but also can be a factor affecting the welfare of farmers in Indonesia. The reasons and problems above that makes researchers want to know and prove the relationship between sectors and problems above.

\section{DATA \\ Agricultural Land Data}

The data of agricultural land used in this study is sourced from the official government agency of Indonesia. This research data for agricultural land sourced from the ministry of agriculture Republic of Indonesia (applications.pertanian.go.id) obtained in 1986-2017 on a macro basis.

\section{Agricultural technology data}

Agricultural technology data obtained from Dummy data, presented and processed in [1] and [2].

\section{Agricultural production data}

The data of agricultural production used in this research is sourced from the official institution of the Indonesian government. Research data is sourced from the Ministry of Agriculture of the Republic of Indonesia (data.go.id) obtained in 1986-2017 on a macro basis.

\section{Welfare Data}

Agricultural welfare data used in this study is sourced from official institutions of the Indonesian government. The research data is sourced from the Central Bureau of Statistics of the Republic of Indonesia (ipm.bps.go.id) obtained in 1986-2017 on a macro basis.

\section{METHOD}

This research is a quantitative descriptive research, where this research combine data from official institution with result and study in field. The data obtained will be processed using statistical analysis tools.

In this study using MANOVA analysis or multivariate analysis, where between free varabel 
and dependent variable more than one. Multivariate statistical analysis is a statistical method that allows us to research more than two simultaneous variables that can be measured and can not be measured. By using multivariate or manova analysis technique, we can analyze the influence of several variables on other variables at the same time ([6]).

The equation of statistical data obtained from research journals can provide information and research progress of the problems between agricultural land and technology affecting the production can be concluded in the statistical formula as follows:

$\boldsymbol{Y}_{1}=\beta_{0}+\beta_{1 z 1}+\beta_{2 z_{2}}+\epsilon_{1}$

Where can be concluded $\mathrm{Y} 1=$ agricultural production; $\beta_{0}=$ Constant; $\mathrm{Z} 1=$ agricultural land; $\mathrm{Z} 2$ $=$ technology; $\in=$ error ([3])

As for the second statistical equation can be explained to describe the analysis mengetahi results of welfare can be summed up as follows:

$\boldsymbol{Y}_{2}=\beta_{0}+\beta_{1 z_{1}}+\beta_{2 z_{2}}+\epsilon_{1}$

From the above equation can be explained to dislodge the meaning of the symbol of the above equation as follows: Y1 $=$ welfare; $\beta_{0}=$ Konstanta; $\mathrm{Z} 1$ = agricultural land; $\mathrm{Z} 2=$ technology; $\epsilon=$ error ([4])

To perfect the test equations and good analytical model can be used to test or prove the results of the analysis can use the general equation in MANOVA or multivariate test, while the above analysis differences using parametric and non parametric method for technological variables, so the analysis with the equation as follows:

$\boldsymbol{Y}_{n z q}=X_{n(p+1)} \beta_{(p+1) q}+\epsilon_{n z q}$

From the results of the above analysis can be explained from the good equation as follows: $\mathrm{Y}=$ agricultural production and welfare; $\mathrm{N}=$ Number of Observations; $\mathrm{Q}=$ Number of $\mathrm{Y} ; \mathrm{Z}=$ agricultural land and Dummy technology; $\mathrm{P}=$ Number of $\mathrm{X} ; \beta=$ coefficient; $\epsilon=$ error. (De Fazio, Manfredi, 2016) (Wossen, tesfamicheal.ect.2017)
TABLE 1

RESULTS ANALYSIS

CORRELATION ANALYSIS BETWEEN RESPONSE VARIABLES

\begin{tabular}{|l|l|l|l|}
\hline & & $\mathbf{Y}_{\mathbf{1}}$ & $\mathbf{Y}_{\mathbf{2}}$ \\
\hline $\mathbf{Y}_{\mathbf{1}}$ & Korelasi & 1 & 0,68 \\
\hline & P-Value & & 0,00 \\
\hline $\mathbf{Y}_{\mathbf{2}}$ & Korelasi & 0,68 & 1 \\
\hline & P-Value & 0,00 & \\
\hline
\end{tabular}

Can be seen in Table obtained p-value $=0.00<\alpha=$ 0.05 then decided to reject $\mathrm{H} 0$ so it can be concluded that inter response variables are dependent, so data can be used in multivariate linear regression analysis because the response variable $\mathrm{Y} 1$ is Production and Y2 Welfare is dependent or correlated.

\section{Parameter Estimate}

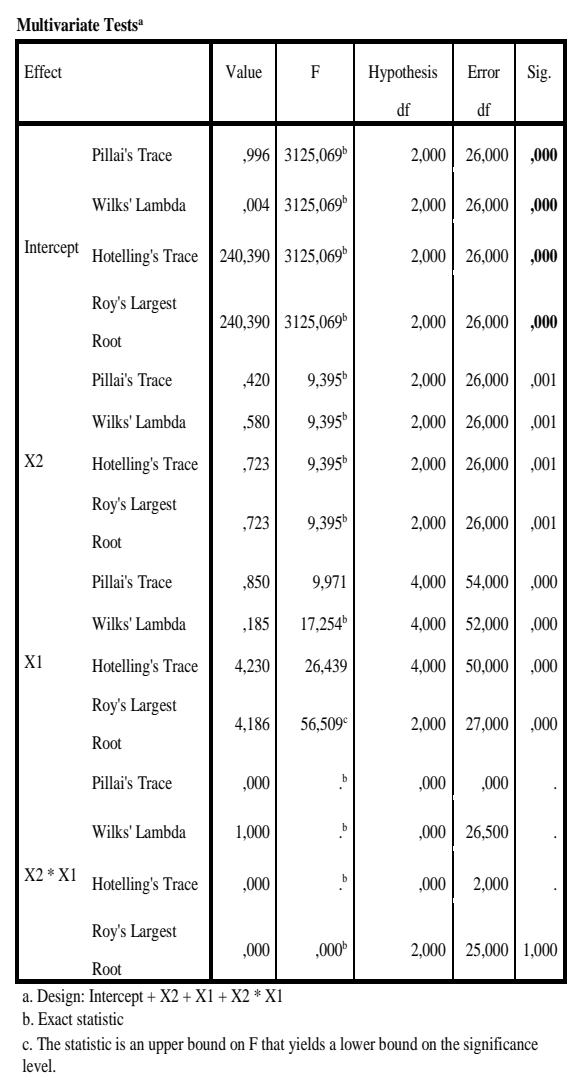


As for the content of this agricultural research can be seen with MANOVA equation, the estimation table can be explained in the following ways:

Variable Harvest Area in general gives a significant effect on the amount of production and welfare. Similarly variable use of technology turned out to have a significant influence on the amount of production and welfare. The interaction between harvested area variables and the provision of technology did not provide significant differences On the amount of production and welfare.

\section{Model formation}

Model formation is used to see the best model in production and welfare.

\begin{tabular}{ccc}
\hline Variabel & & $\beta$ \\
& Variabel & \\
\hline & & \\
\hline & Konstan & 842113,429 \\
$Y 1$ & $X 1$ & $-63979,200$ \\
& $X 2$ & $-253909,229$ \\
& Konstan & 69,990 \\
& $X 1$ & $-7,293$ \\
$Y 2$ & $X 2$ & $-4,380$ \\
\hline
\end{tabular}

For the best model of multivariate linear regression for variable of production quantity count (Y1) and Welfare (Y2) based on parameter estimation and parameter estimation test are as follows:

$\mathrm{Y}_{1}=842.113,429-63.979,200 \mathrm{X}_{1}-253.909,229 \mathrm{X}_{2}$

$\mathrm{Y}_{2}=69,990-7,293 \mathrm{X}_{1}-4,380 \mathrm{X}_{2}$

The results can be concluded from all the above variables can be seen that the problems that must be addressed above must be addressed because the impact resulting from agricultural dilemma has significant effect, agricultural land and technology to agricultural agricultural welfare production. This can result in the decrease of agricultural products and pengaguran caused due to the growing technology and also the narrowing of land pertania especially on the island of Java.

\section{CONCLUSIONS}

Data can be used in multivariate linear regression analysis because the response variable $\mathrm{Y} 1$ is Production and Y2 Welfare is dependent or correlated. Variable Harvest Area in general gives a significant effect on the amount of production and welfare. Similarly variable use of technology turned out to have a significant influence on the amount of production and welfare. The interaction between harvested area variables and the provision of technology did not provide significant differences to the amount of production and welfare.

\section{ACKNOWLEDGMENT}

Thanks to LPDP BUDI DN as the main sponsor in publishing this journal and also support from PPP S3 Economic Science UNAIR which always give direction, regards and terimaksih to Promoter S3 Economic Science UNAIR Mr. Tri Haryanto who has provided support and direction in this research journal and as well as fellow S3 1 Ekonomi UNAIR Economy who always the spirit of providing moral support and knowledge

\section{REFERENCES}

[1] De Fazio, Manfredi. (2016)," Agriculture and sustainability of the welfare: the role of the short supply chain", Florence "Sustainability of Well-Being International Forum": Food for Sustainability and not just food, FlorenceSWIF2015. Agriculture and Agricultural Science Procedia 8 (2016) $461-466$

[2] Wossen, tesfamicheal.ect. (2017)," productivity and welfare eff ects of nigeria's e-voucher-based input subsidy program", Http://dx.doi.org/10.1016/j.worlddev.2017.04.021. World development vol. 97, pp. 251-265, 2017 0305-750x/ 2017 the authors. Published by elsevier ltd. This is an open access article under the cc by license (http://creativecommons.org/licenses/by/4.0/).

[3] G. Koleva, Nikolinka.ect. (2010)," Pesticide externalities from the US agricultural sector - The impact of internalization, reduced pesticide application rates, and climate change", Earth System Science 2010: Global Change, Climate and People, Procedia Environmental Sciences 6 (2011) 153-161.

[4] Yuanchang, Xu.ect. (2010)," The optimal boundary of political subsidies for agricultural insurance in welfare economic prospect," International Conference on Agricultural Risk and Food Security 2010. Agriculture and Agricultural Science Procedia 1 163-169

[5] Pertanian, (2017).http://aplikasi.pertanian.go.id/bdsp/ IPM,2017. http://ipm.bps.go.id/

[6] Warsono, Jonathan. (2017), “Teori Analisis Multivariat”, Http://www.jonathansarwono.info/mvariat/multivariat.htm 